\title{
Behaviour of a High Frequency Parallel Quasi Resonant Inverter Fitted Induction Heater with Different Switching Frequencies
}

\author{
Avijit Chakraborty*, Pradip Kumar Sadhu**, Kallol Bhaumik*, Palash Pal*, Nitai Pal** \\ * Departement of Electrical Engineering, Saroj Mohon Institute of Technology (A Unit of Techno-India group), \\ Guptipara, Hooghly-712512, India \\ ** Electrical Engineering Department, Indian School of Mines (under MHRD, Govt. of India), Dhanbad - 826004, India
}

\begin{tabular}{l} 
Article Info \\
\hline Article history: \\
Received May 9, 2015 \\
Revised Nov 23, 2015 \\
Accepted Dec 16, 2015 \\
\hline Keyword: \\
High Frequency Inverter \\
IGBT \\
PFM \\
PSIM \\
Quasi-Resonant \\
THD
\end{tabular}

Article Info

Received May 9, 2015

Revised Nov 23, 2015

Accepted Dec 16, 2015

\begin{abstract}
This paper investigates the behavior of a high frequency parallel quasiresonant inverter fitted domestic induction heater with different switching frequencies. The power semiconductor switch Insulated Gate Bipolar Junction Transistor (IGBT) is incorporated in this high frequency inverter that can operate under ZVS and ZCS conditions during the switching operations at certain switching frequency to reduce switching losses.The proposed induction heating system responds to three different switching frequencies with providing different results. An Insulated Gate Bipolar Junction Transistor (IGBT) provides better efficiency and faster switching operations. After the complete study of the proposed induction heating system at the selected switching frequencies, the results are compared and it is decided that most reliable, efficient and effective operations from the proposed induction heater can be obtained if the switching frequency is selected slightly above the resonant frequency of the tank circuit of the resonant inverter. The proposed scheme is analyzed using Power System Simulator (PSIM) environment.
\end{abstract}

Copyright (C) 2016 Institute of Advanced Engineering and Science. All rights reserved.

\section{Corresponding Author:}

\author{
Avijit Chakraborty \\ Departement of Electrical Engineering, \\ Saroj Mohon Institute of Technology (A Unit of Techno-India group). \\ Guptipara, Hooghly-712512, India. \\ Email: a.chakt@gmail.com
}

\section{INTRODUCTION}

Induction heating technology is widely used in induction based cookers for its cleanliness, pollutionfree, very fast heating, high efficiency and safety [1-3]. It is a contactless heating process, in which a very high frequency current is sent to a working coil through power semiconductor switches, which produces an eddy emf in the working coil [3]. This emf produces a very high frequency alternating magnetic field in the coil and sufficient heat will be generated in the work piece. The frequency of the inductor current depends on the size of the heating coil, penetration depth and the electromagnetic coupling. In induction heating process a pot is directly heated by the induced eddy current produced by this magnetic field. Induction heating process is very much suitable for domestic cooking, melting, surface hardening, brazing and soldering [6-9, 15]. Now a day, it is also applied to hyperthermia treatment and blood reheating under medical application $[3,9]$.

In this paper an IGBT based parallel quasi resonant inverter is proposed and implemented for induction heating application and its performance and behaviour are analyzed using PSIM software simulation under three different switching frequencies, which are $15 \mathrm{kHz}, 32 \mathrm{kHz}$ and $45 \mathrm{kHz}$ respectively. The incorporated resonant inverter has the resonant frequency of $30 \mathrm{kHz}$. It is found that maximum energy transfer 
to the work piece from the working coil occurs whenever the switching frequency is set closer to the resonant frequency.The proposed quasi resonant inverter control scheme is based on variable frequency or Pulse Frequency Modulation (PFM) control method. A typical induction heating system is shown in the following figure.

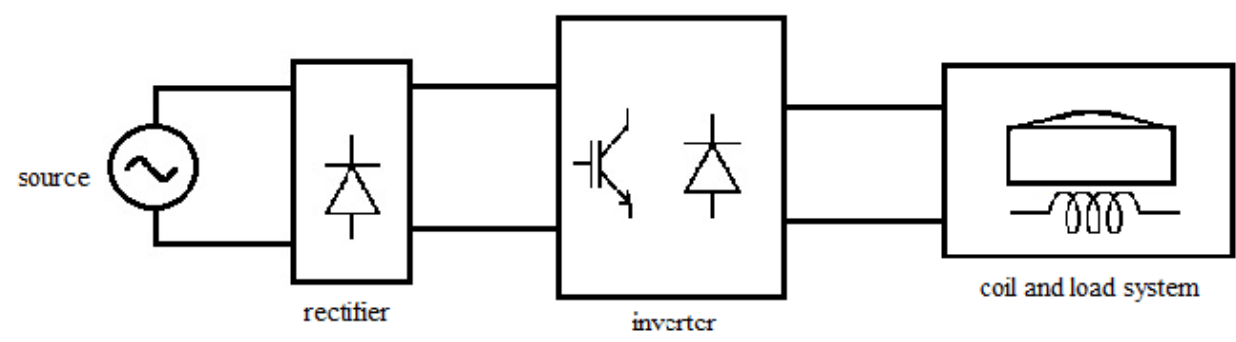

Figure 1. Basic Induction heating system

\section{MERITS OF IGBT OVER OTHER POWER SEMI-SEMICONDUCTOR SWITCHES IN QUASI-RESONANT INVERTER}

The power semiconductor switch like IGBT is preferable over other power semiconductor switches in parallel quasi resonant inverter due to the following reasons [4-5, 14-18]:

- $\quad$ IGBT has less switching loss [10-13].

- It provides faster switching speed.

- It has less ON state drop.

- It is a better voltage controlled device.

- It provides better energy efficient operation.

\section{PARALLEL QUASI-RESONANT CONVERTER TOPOLOGY} IGBT.

The following figure 2 depicts a certain topology of a parallel quasi resonant inverter using single

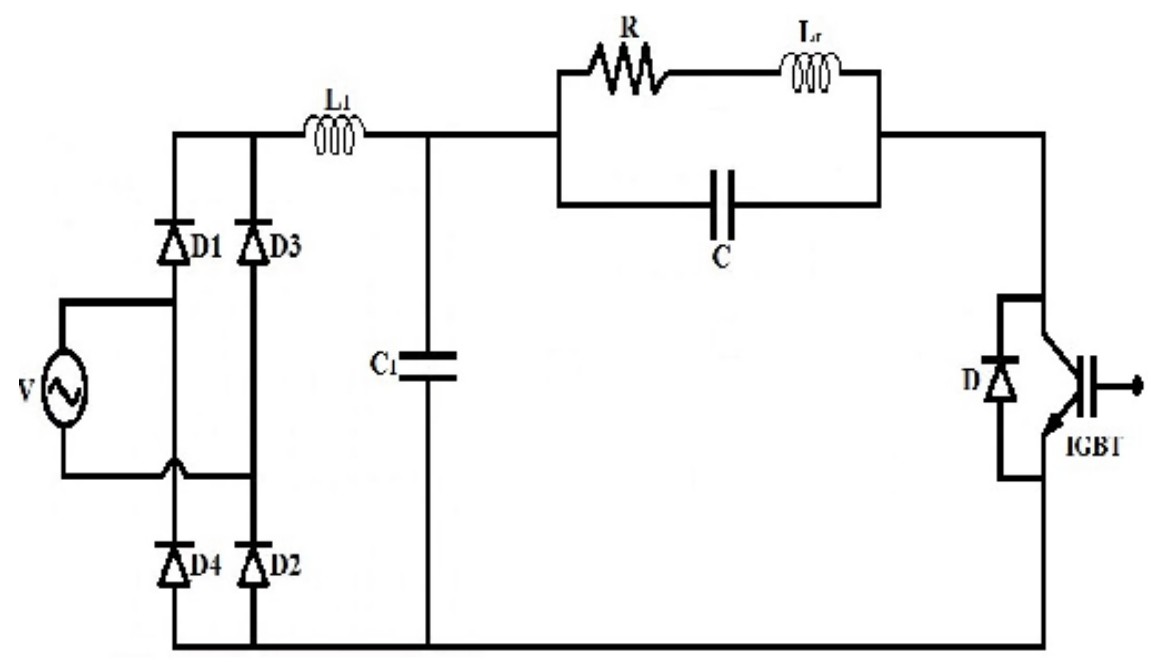

Figure 2. IGBT based parallel quasi resonant inverter

Quasi-Resonant (QR) converters are widely used as high frequency AC power sources in induction heating applications. Such converters are very cost effective for the domestic appliances because it requires only one IGBT, and only one resonant capacitor C. Quasi-Resonant converters might be considered as a 
reasonable compromise between cost and effective performance. Only one drawback of this family of converter is that it has limited regulation range. Besides it is desirable to operate in the ZVS mode, induction heating based cookers are normally allowed to operate at power levels at which the resonant voltage does not quite reach zero. At power levels lower than this, the overall power modulation is pulse-width-modulated at a very low frequency to limit the losses. In this low power mode of operation, the unit may operate at the low power level for very small time duration and then it will be OFF for small time duration. This is much shorter than the thermal time constant of the pan and its contents, and has no negative effect of the cooking operation; however, it does help to maximize the performance of the power stage and limit the temperature rise of the IGBT switch. For a given loading condition (i.e. a certain pot), maximum power level and maximum supply voltage, the peak voltage rating for the switch and resonant capacitor, can be calculated from Quasi- Resonant theory and can be approximated by the following equation.

$$
\mathrm{E}=\frac{1}{2} \mathrm{CV}_{\text {res }}^{2}
$$

Where, $\mathrm{E}$ is the energy stored in the inductor coil during the on period Ton. $\mathrm{C}$ is the capacitance of the resonant capacitor and Vres is the resonant voltage.

$$
\text { Thus, } \mathrm{V}_{\text {res }}=\sqrt{\frac{2 \mathrm{E}}{\mathrm{C}}}
$$

Similarly, when this energy is exchanged to the resonant capacitor, then it can be represented by the equation

$$
\mathrm{E}=\frac{1}{2} \mathrm{~L}_{\mathrm{r}} \mathrm{I}_{\text {peak }}^{2}
$$

And the $\mathrm{I}_{\text {peak }}$ is directly proportional to Ton and dc bus voltage $\mathrm{V}_{\mathrm{dc}}$ by the following equation

$$
\mathrm{I}_{\text {peak }}=\operatorname{Ton} \cdot \frac{\mathrm{V}_{\mathrm{dc}}}{\mathrm{L}_{\mathrm{r}}}
$$

The resonant voltage $\mathrm{V}_{\text {res }}$ can be expressed as

$\mathrm{V}_{\text {res }}=\alpha \mathrm{V}_{\mathrm{dc}}$ where, $\alpha$ is the duty cycle. So, it can expressed as $\alpha=\frac{\mathrm{T}_{\text {on }}}{\mathrm{T}}$

And if $\omega_{0}$ be the resonant frequency, then $\omega_{0}=\frac{1}{\sqrt{\mathrm{L}_{\mathrm{r}} \mathrm{C}}}=\frac{1}{\mathrm{~T}}$

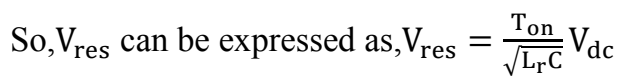

\section{OPERATIONAL MODES OF PARALLEL QUASI-RESONANT CONVERTER}

The main quasi-resonant power circuit contains a parallel converter. It consists of full bridge diode rectifier, a passive LC filter and an anti-parallel diode connected across the IGBT. The circuit generates high frequency switching by turning ON the IGBT under ZVS condition while the diode is in the conducting state. The resonant circuit consists of resonant inductor $\operatorname{Lr}$ (coil inductance and resistance) and a resonant capacitor C. There are four modes of operation exist within one switching cycle as follows:

\section{(i) Mode-1 IGBT on, Diode off}

In this mode as shown in figure 3, switch Q1 is switched on with suitable gate voltage and current flows from the collector to the emitter of Q1. The current through the L gradually rises so that it is storing energy providing ZVS turn on of the IGBT switch Q1 following the diode conduction. In this mode, current passes through a simple R-L circuit.

Mode -1 can be expressed by the following equation

$$
\mathrm{Ri}+\mathrm{L}_{\mathrm{r}} \frac{\mathrm{di}}{\mathrm{dt}}=\mathrm{V}_{\mathrm{dc}}
$$




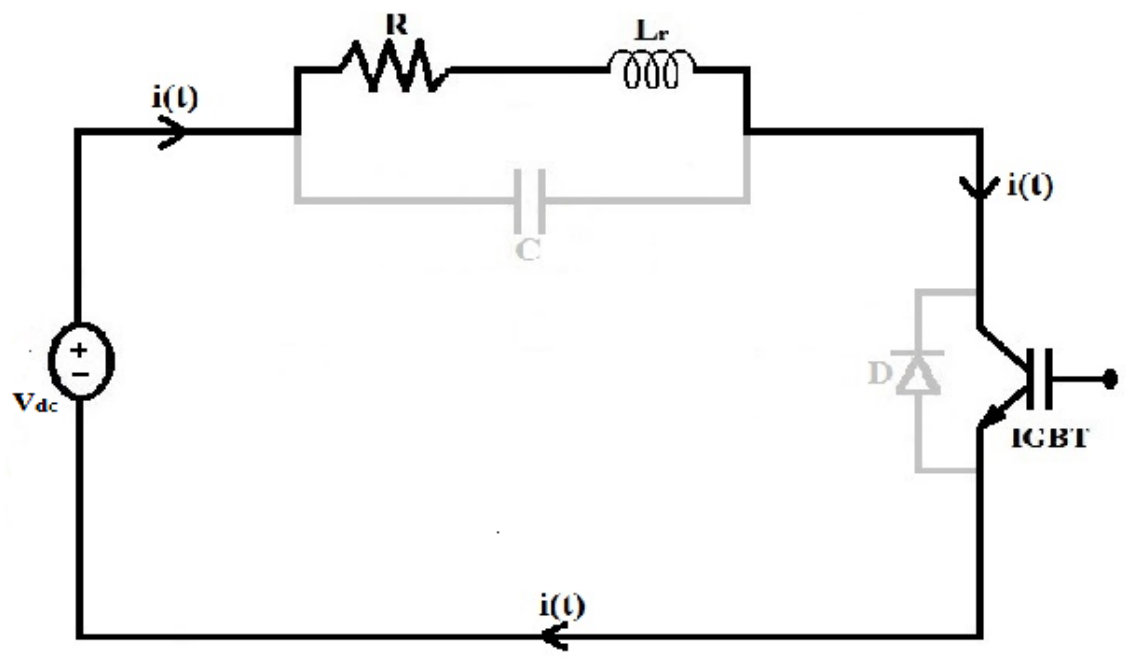

Figure 3. Mode 1 equivalent circuit

(ii) Mode-2 IGBT off, Diode off

When the switch Q1 is turned off, the current will still be increasing and finally attains the peak value. At this instant, the energy stored in $\mathrm{L}$ begins to transfer to $\mathrm{C}$. This mode is a self-resonating mode of LC oscillating circuit which is shown in figure 4.

Mode -2 can be expressed by the following equation

$$
\mathrm{Ri}+\mathrm{L}_{\mathrm{r}} \frac{\mathrm{di}}{\mathrm{dt}}+\frac{1}{\mathrm{C}} \int \mathrm{idt}=0
$$

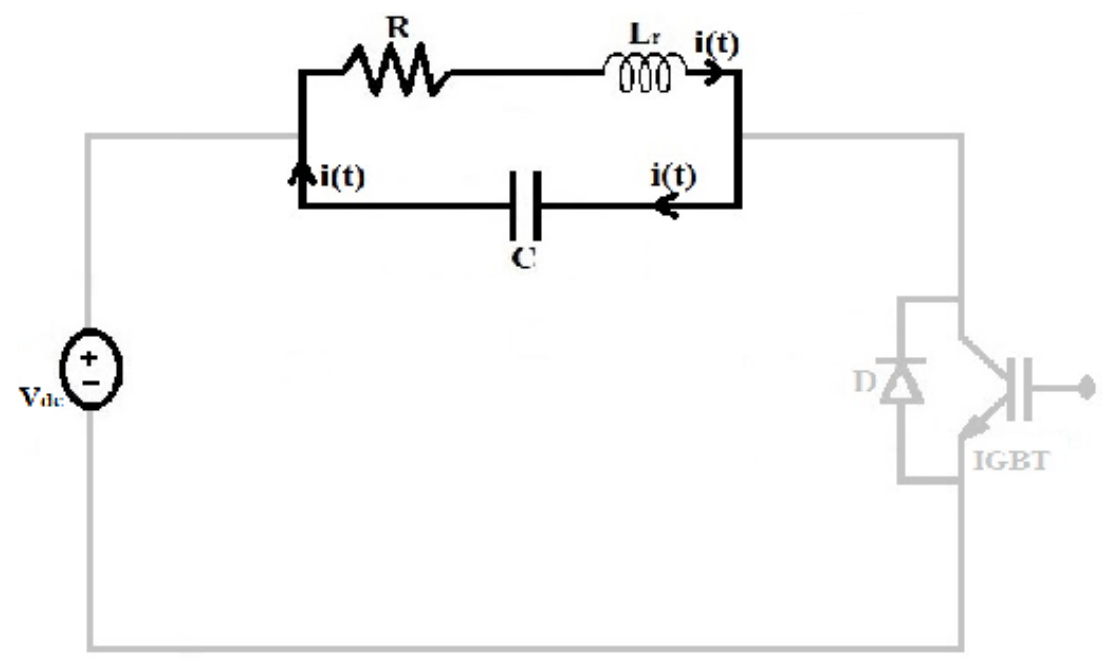

Figure 4. Mode 2 equivalent circuit

(iii) Mode-3 IGBT off, Diode off

In this mode as shown in figure 5, after the current through $\mathrm{L}$ becomes zero, the capacitor $\mathrm{C}$ begins to discharge through $\mathrm{L}$ and a current in the reverse direction flows. The voltage across $\mathrm{L}$ increases and polarity is reversed.

Mode -3 can be expressed by the following equation

$$
\frac{1}{C} \int i d t=R i+L_{r} \frac{d i}{d t}
$$




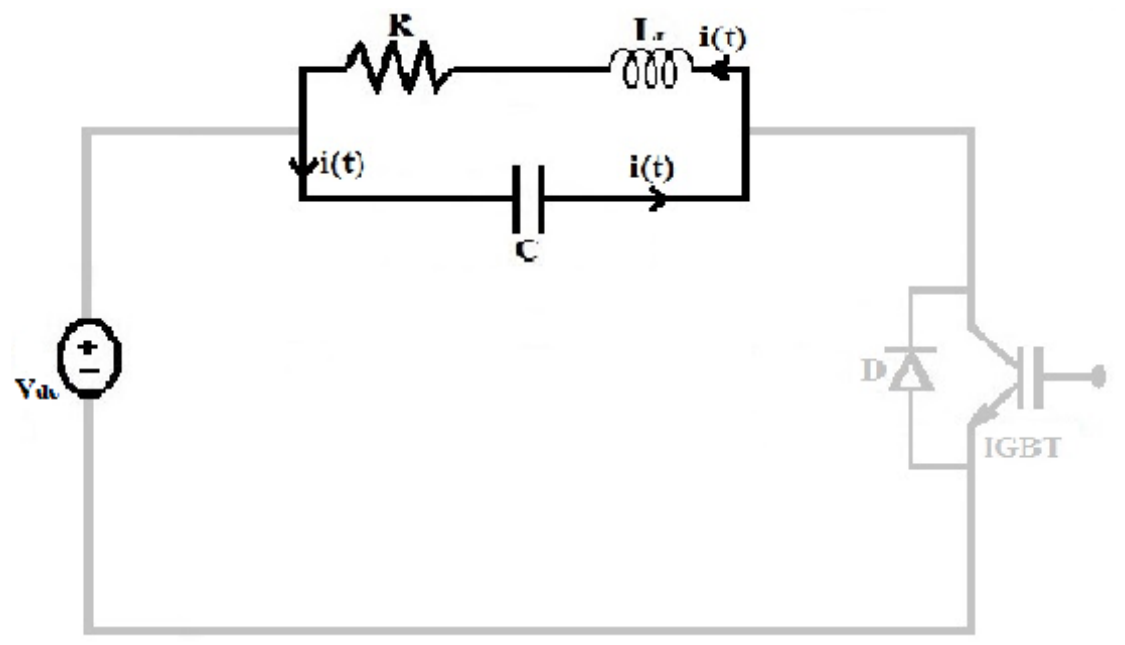

Figure 5. Mode 3 equivalent circuit

\section{(iv) Mode-4 IGBT off, Diode on}

In this mode as shown in figure 6 , when the reversed polarity across $\mathrm{L}$ exceed $\mathrm{V}_{\mathrm{dc}}$, the diode becomes forward biased and the current of $\mathrm{L}$ flows through this diode until this current reaches the zero. After mode-4, mode-1 starts with IGBT on under ZCS condition.

Mode -4 can be expressed by the following equation

$$
\mathrm{L}_{\mathrm{r}} \frac{\mathrm{di}}{\mathrm{dt}}-\mathrm{V}_{\mathrm{dc}}=\mathrm{Ri}
$$

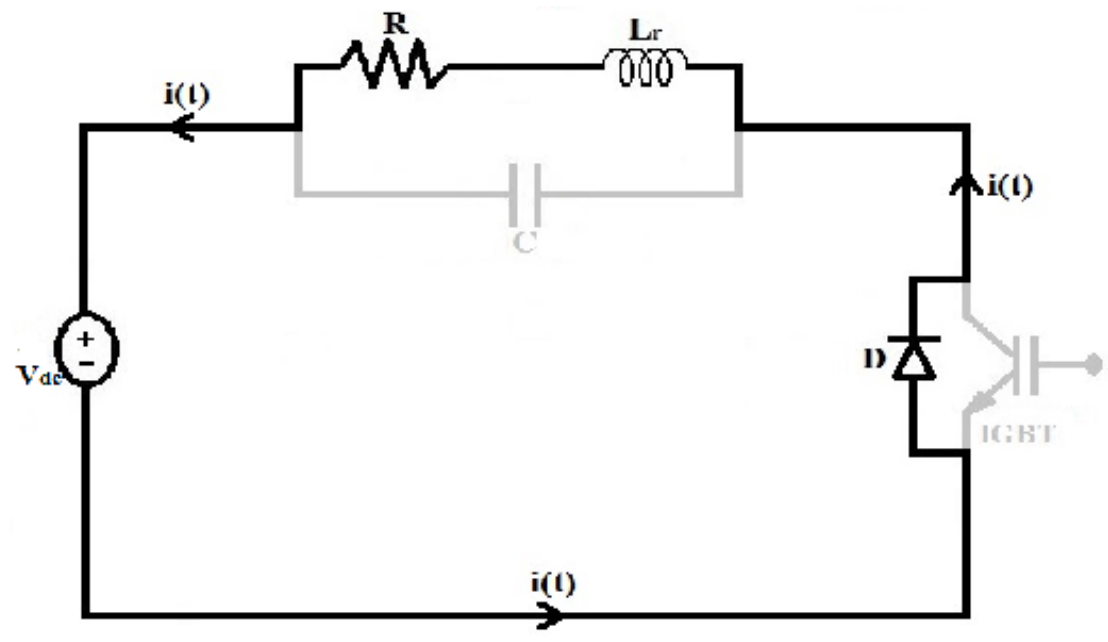

Figure 6. Mode 4 equivalent circuit

At the end mode-4, one cycle operation of the quasi-resonant converter is completed. After that the circuit operation repeats from mode- 1 and so on.

In the following figure 7 different voltage, current and Gate signal waveforms are shown for the proposed system at different modes. 


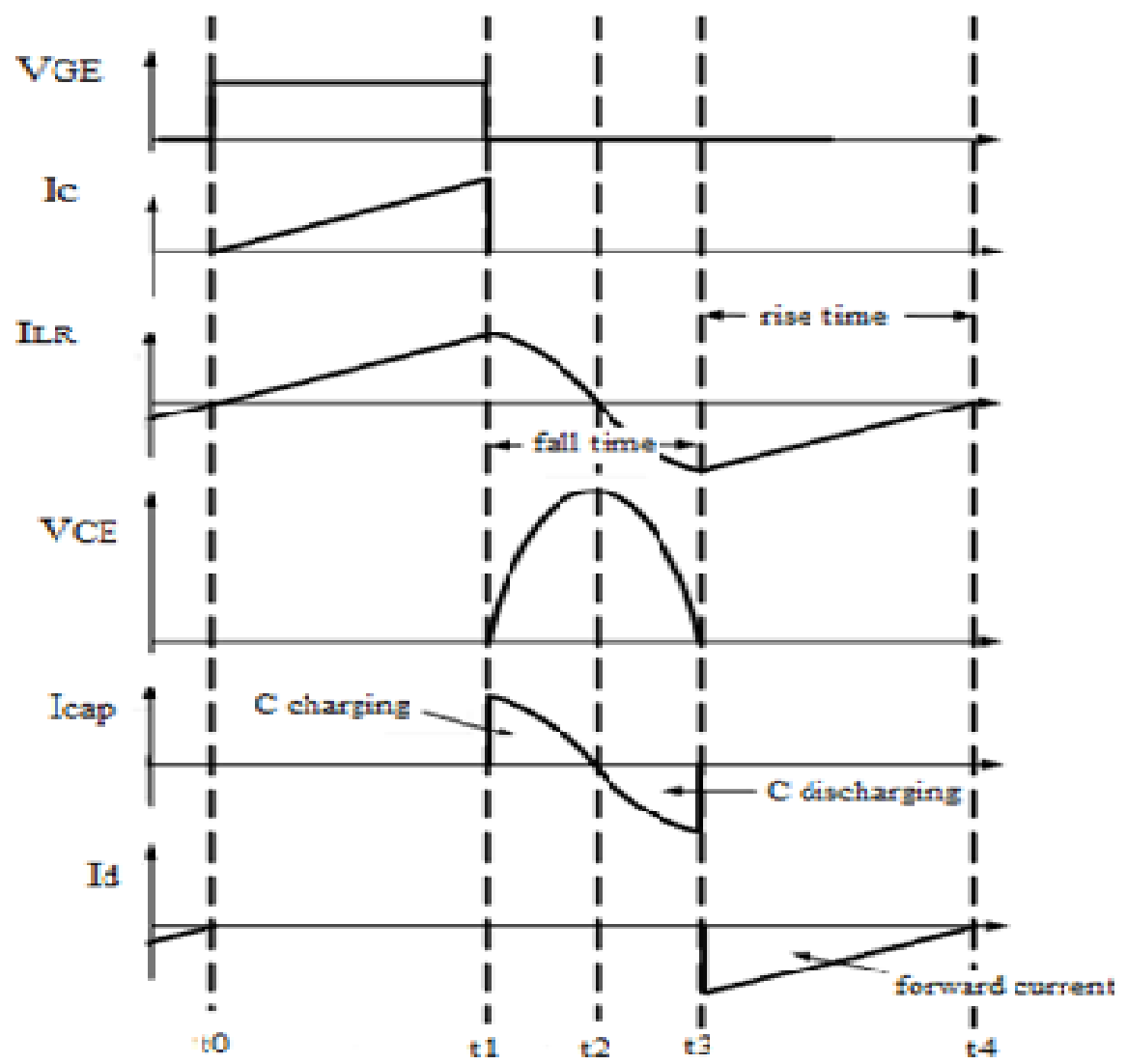

Figure 7. Typical voltage, current and gate signals

Where, $\mathrm{V}_{\mathrm{GE}}=$ Gate voltage of IGBT, $\mathrm{I}_{\mathrm{C}}=\mathrm{IGBT}$ collector current, $\mathrm{I}_{\mathrm{LR}}=$ Inductor current, $\mathrm{V}_{\mathrm{CE}}=$ voltage across IGBT, $\mathrm{I}_{\text {cap }}=$ Capacitor current, $\mathrm{I}_{\mathrm{D}}=$ Diode current.

The collector current of the IGBT can be expressed as $I_{c}=\frac{V_{c c} T_{r}}{2 L_{r}}$

Where, $\mathrm{T}_{\mathrm{r}}=$ rise time.

And the collector voltage can be expressed as,

$\mathrm{V}_{\mathrm{ce}}=\mathrm{V}_{\mathrm{cc}}\left(1+\frac{\pi \mathrm{T}_{\mathrm{r}}}{2 \mathrm{~T}_{\mathrm{f}}}\right)$

Where $\mathrm{T}_{\mathrm{f}}=$ fall time.

From the above mentioned four modes of operations, the operation over a switching period can be described by two circuit modes.

First mode begins when the IGBT switch is turned on at ZVS condition with initial conditions $\mathrm{V}_{\mathrm{c}}(0)$ $=0$ and $\mathrm{i}_{\mathrm{LR}}(0)=0$, the inductor current iLR at any instant can be expressed as

$\mathrm{i}_{\mathrm{LR}}(\mathrm{t})=\frac{\mathrm{V}_{\mathrm{dc}}}{\mathrm{R}}\left(1-\mathrm{e}^{-\tau \mathrm{t}}\right)$

Where, $\tau=\frac{\mathrm{Lr}}{\mathrm{R}}=$ time constant of the circuit. Peak value of the current is $\frac{\mathrm{V}_{\mathrm{dc}}}{\mathrm{R}}$ at $\mathrm{t}=\mathrm{t} 2$. This mode continues till the switch is turned off at $\mathrm{t}=\mathrm{t} 1$

The second mode starts at $\mathrm{t}=\mathrm{t} 1$ when the IGBT is turned off at $\mathrm{t}=\mathrm{t} 1$. Considering the mesh formed by the source voltage $\mathrm{V}_{\mathrm{dc}}$, inductance $\mathrm{L}_{\mathrm{r}}$ and resistance $\mathrm{R}$ with initial conditions $V_{c}(0)=0$ and $\mathrm{i}_{\mathrm{LR}}(0)=\mathrm{I}_{\mathrm{LR} 1}$, the corresponding equations are 


$$
\begin{aligned}
& \mathrm{i}_{\mathrm{LR}}(\mathrm{t})=\left(\frac{\omega_{0}}{\omega}\right)\left(\mathrm{e}^{-\alpha \mathrm{t}}\right)\left[\left(\mathrm{V}_{\mathrm{dc}}-\mathrm{V}_{\mathrm{c}}\right) \sqrt{\frac{\mathrm{C}}{\mathrm{L}_{\mathrm{r}}}} \sin \omega \mathrm{t}+\mathrm{I}_{\mathrm{LR} 1} \cos (\omega \mathrm{t}+\theta)\right] \\
& \mathrm{V}_{\mathrm{c}}(\mathrm{t})=\mathrm{V}_{\mathrm{dc}}+\left(\frac{\omega_{0}}{\omega}\right)\left(\mathrm{e}^{-\alpha \mathrm{t}}\right)\left[\left(\mathrm{V}_{\mathrm{dc}}-\mathrm{V}_{\mathrm{c}}\right) \cos (\omega \mathrm{t}-\theta)+\mathrm{I}_{\mathrm{LR} 1} \sqrt{\frac{\mathrm{L}_{\mathrm{r}}}{\mathrm{C}}} \sin \omega \mathrm{t}\right]
\end{aligned}
$$

for during the resonant cycle. where, $\alpha, \omega$ and $\theta$ are constants and are given by $\alpha=\frac{R}{2 L_{r}}, \omega_{0}=\sqrt{L_{r} C}$, $\omega=\sqrt{\omega_{0}^{2}-\alpha^{2}}, \theta=\tan ^{-1}\left(\frac{\alpha}{\omega}\right)$

\section{TOTAL HARMONIC DISTORTION (THD)}

It is the measure of harmonic presence in a non-sinusoidal periodic waveform. It is represented by the following expression

$$
\mathrm{THD}=\frac{\sum\left(\mathrm{I}_{0 \mathrm{rms}}^{2}-\mathrm{I}_{1 \mathrm{rms}}^{2}\right)^{\frac{1}{2}}}{\mathrm{I}_{1 \mathrm{rms}}}
$$

where, $\mathrm{I}_{\text {0rms }}$ is the root mean squared (RMS) value of any non-sinusoidal current and $\mathrm{I}_{1 \mathrm{rms}}$ is the root mean squared (RMS) value of the fundamental harmonic present in that current. THD gives an idea about how close a non-sinusoidal waveform close to its fundamental in shape.

\section{SWITCHING LOSS}

Switching operation includes turn-ON and turn-OFF losses respectively. Generally switching losses need to be estimated. Estimating the IGBT switching loss as given below,

$$
P_{\text {switch }}=\frac{I_{\text {on }} \mathrm{V}_{\text {off }} t_{\text {switch }} \mathrm{f}_{\text {switch }}}{2}
$$

\section{PSIM SIMULATION}

The developed PSIM schematic circuit diagram is shown in Figure 8, in which four diodes are used in a full-bridge rectifier and a high frequency inverter using only one IGBT.

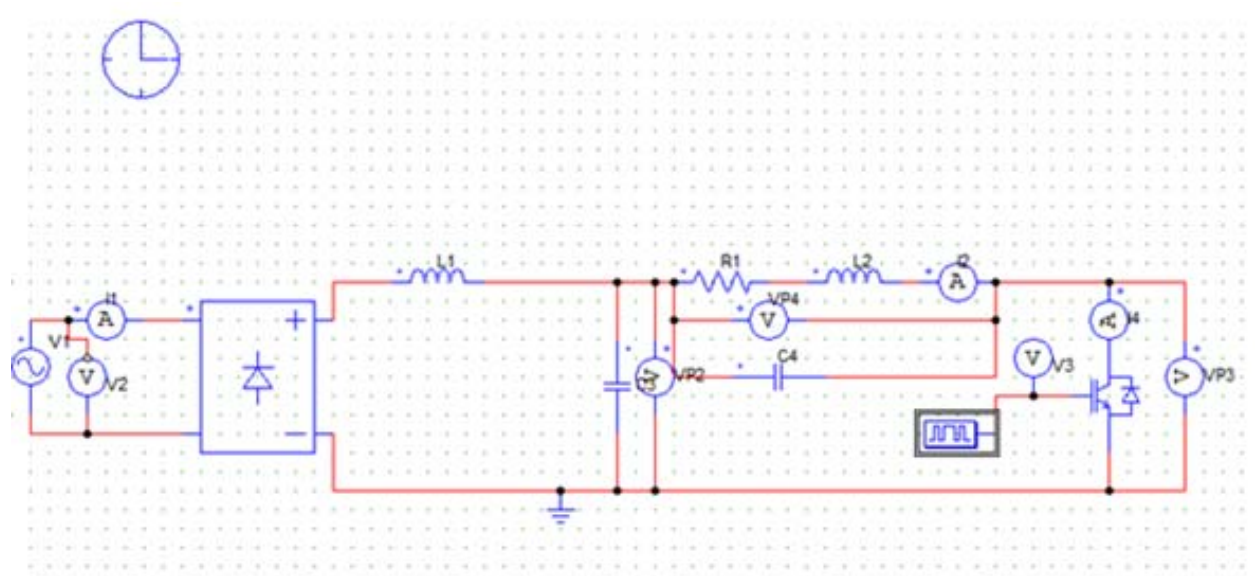

Figure 8. PSIM simulation of the proposed parallel Quasi-resonant inverter

\section{RESULTS AND DISCUSSIONS}

The main equivalent circuit of the proposed parallel quasi resonant inverter is shown in Figure 2. The different parameters are shown in Table 1. The four modes (from mode-1 to mode-4) will repeat on the basis of specified IGBT on time and off time. The depth of penetration of the heat in the cooking pan is inversely proportional to the operating frequency and the operating time period is the inverse of operating frequency. Thus after changing the on-off time of the IGBT, the operating frequency and the depth of 
penetration of heat can be controlled. In the present work, the proposed parallel quasi-resonant circuit is tested under three different switching frequencies which are $15 \mathrm{kHz}, 32 \mathrm{kHz}$ and $45 \mathrm{kHz}$ respectively. The resonant frequency of the tank circuit is $30 \mathrm{kHz}$. When the switching frequency is selected at $32 \mathrm{kHz}$ close to the resonant frequency, then from Figure 9 it is shown that switching operations follow the ZVS and ZCS conditions ensuring less switching loss with higher efficiency. The switching frequency at $32 \mathrm{kHz}$ also makes the input current sinusoidal with less Total Harmonic Distortion (THD) as given in Table 2. The output power factor is also the maximum at this switching frequency, which is given in Table 3 . Besides, greater Total Harmonic Distortion (THD) at the output current also provides large amount of heat geneartion. Therefore, the selection of the switching frequency slightly above the resonant frequency is mostly beneficial. When the switching frequency is selected at $15 \mathrm{kHz}$ much less than the resonant frequency, then from Figure, it is shown that the switching operation does not follow the ZVS and ZCS conditions that causes high switching losses and efficiency reduces, besides the inverter operates in capacitive mode. Since, the THD of the input source current is very high at this switching frequency, which makes the input source current non-sinusoidal and thus the input source voltage may contain unwanted harmonics. As such installation of an ac filter is required at the input side and this will make the induction heater costlier. Besides, this low switching frequency may cause an undesirable audible noise. The output current also has a low THD compared to $32 \mathrm{kHz}$ switching frequency as shown in Table 2. So, the selection of switching frequency at $15 \mathrm{kHz}$ is generally avoided. The selection of switching frequency at $45 \mathrm{kHz}$ above the resonant frequency gives a high THD value of the output current and is fruitful for induction heating purpose, but this is also avoided because of the switching operations do not follow the ZVS and ZCS operations and thus produce high switching losses that is shown Table 3. The power factors of the output power are less for both $15 \mathrm{kHz}$ and $45 \mathrm{kHz}$ switching frequencies compared to switching frequency $32 \mathrm{kHz}$ as shown in Table 3.

Table 1. Design parameters of Parallel quasi resonant inverter Parameters

Parameters
Coil Inductance $(\mathrm{Lr})=47 \mu \mathrm{H}$
Main supply voltage $=230 \mathrm{Volts}$
Internal Resistance of the coil $(\mathrm{R})=1 \mathrm{ohm}$
Operating frequency $=30 \mathrm{kHz}$
Capacitor $(\mathrm{C} 1)=0.5 \mu \mathrm{F}$
Resonant capacitor $(\mathrm{C})=0.6 \mu \mathrm{F}$
Inductor $(\mathrm{L} 1)=100 \mu \mathrm{H}$

Table 2. Input Current THD and Output Current THD versus Switching frequency

\begin{tabular}{ccc}
\hline Switching frequency $(\mathrm{kHz})$ & Input Current THD value (percent) & Output Current THD value (percent) \\
\hline $15 \mathrm{kHz}$ & $32.00 \%$ & $93.37 \%$ \\
$32 \mathrm{kHz}$ & $2.66 \%$ & $103.13 \%$ \\
$45 \mathrm{kHz}$ & $1.76 \%$ & $146.57 \%$ \\
\hline
\end{tabular}

Table 3. Switching Loss and Output Power Factor versus Switching frequency

\begin{tabular}{ccc}
\hline Switching frequency(kHz) & Switching Loss (watt) & Output Power Factor \\
\hline $15 \mathrm{kHz}$ & 41.43 & 0.2585 \\
$32 \mathrm{kHz}$ & 20.33 & 0.3178 \\
& 56.27 & 0.2336 \\
\hline
\end{tabular}




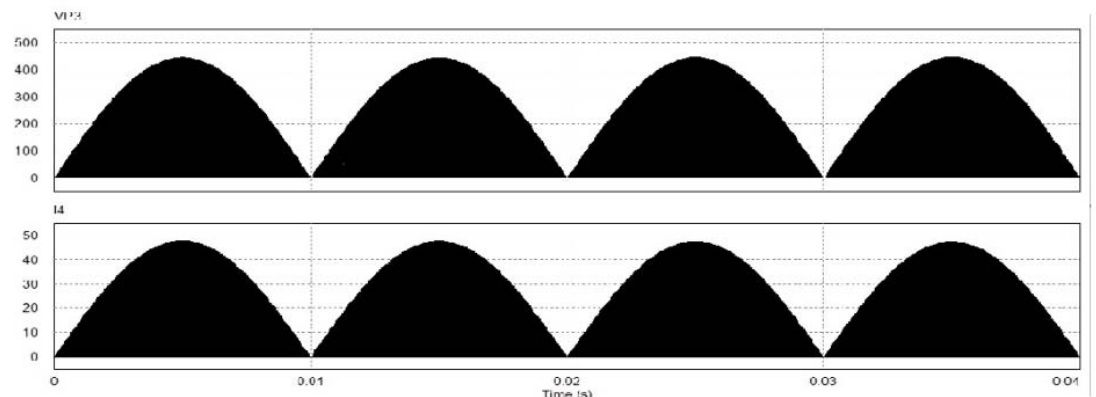

Figure 9. Voltage across IGBT and current through IGBT at switching frequency $=32 \mathrm{kHz}$

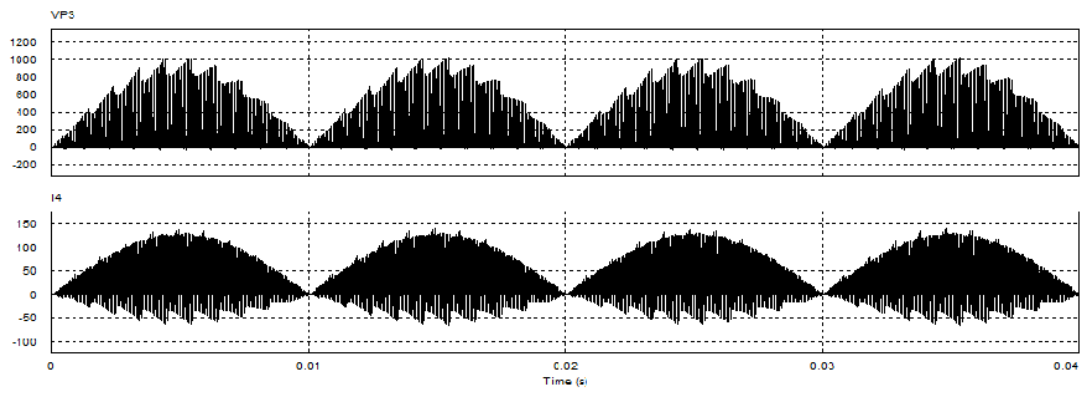

Figure 10. Voltage across IGBT and current through IGBT at switching frequency $15 \mathrm{kHz}$

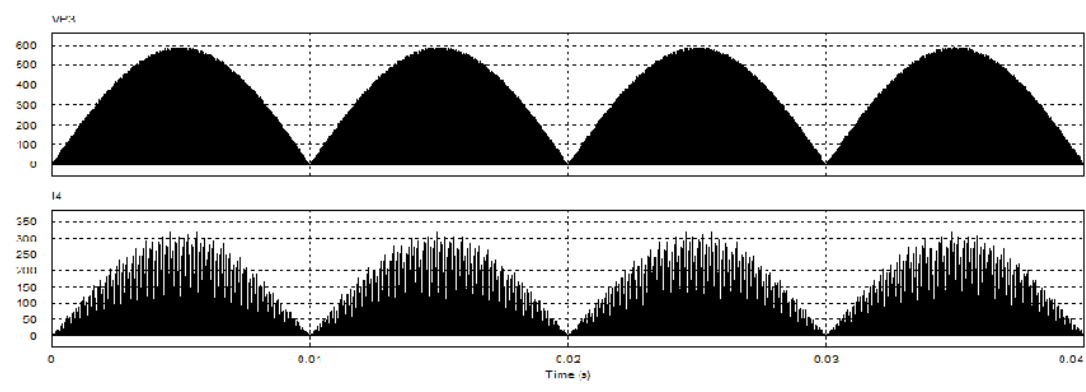

Figure 11. Voltage across IGBT and current through IGBT at switching frequency $45 \mathrm{kHz}$

\section{CONCLUSION}

In this paper, the circuit of a parallel quasi- resonant inverter based induction heating system is analysed mathematically and also its performance is verified using PSIM software. The principle of inverter operation has been presented and different simulated waveforms are shown at three different switching frequencies $15 \mathrm{kHz}, 32 \mathrm{kHz}$ and $45 \mathrm{kHz}$ respectively. It is also shown that at switching frequency $32 \mathrm{kHz}$ near to the resonant frequency only provides ZVS or ZCS operation during turn-ON and turn-OFF conditions and provides the minimum switching losses with an improved output power factor and overall performance is improved. It can be concluded that parallel quasi- resonant based inverter can be used in cost effective induction heating applications.

\section{REFERENCES}

[1] M. Miyamae, T. Ito, K. Matsuse, M. Tsukahara, "Performance of a High Frequency Quasi-Resonant Inverter with Variable-Frequency Output for Induction Heating”, in Proc. IPEMC'12, PD0123, 2012.

[2] Chudjuarjeen, S. and Koompai, C., 2007, “A High-Frequency Induction Cooker using Qusai-resonant Converter', ECTI-Conf. 2007 pp.378-381.

[3] S. Okudaira and K. Matsuse, "New quasi-resonant inverter with short circuit switches across the resonant capacitor and its operating characteristics”, Trans. Inst. Elect. Eng. Jpn, Vol. D-125, No.8, pp-793-799, 2005 
[4] S. Okudaira and K. Matsuse, "Adjustable Frequency Quasi-Resonant Inverter Circuits Having Short-Circuit Switch Across Resonant Capacitor”, IEEE Trans. Power Electron., vol. 19, no. 4, pp. 1830-1838, 2008

[5] Acero, M. Burdio et al. "Domestic Induction Appliances: An Overview of Recent Research", IEEE Industry Applications Magazine, pp. 39-47, Mar/Apr 2010

[6] Y.S. Kwon, S.B. Yoo, D.S. Hyun, "Half-bridge series resonant inverter for induction heating applications with load adaptive PFM control strategy", Record of IEEE Applied Power Electronics Conference \& Exhibition, TX, USA, pp. 575-581, 1999

[7] O. Lucía, J.M. Burdío, I. Millán, J. Acero, and D. Puyal, "Load- adaptive control algorithm of half-bridge series resonant inverter for domestic induction heating", IEEE Transactions on Industrial Electronics, vol. 56, no. 8, pp. 3106-3116, August 2009.

[8] O. Lucía, P. Maussion, E. Dede, and J.M. Burdio, "Induction heating technology and its applications: Past Developments, current technology, and future challenges", IEEE Transactions on Industrial Electronics, Vol.61, pp. 2509-2520, May 2014.

[9] Y. Kawaguchi, E. Hiraki, T. Tanaka, M. Nakaoka, A. Fujita, and H. Omori, "Feasible evaluation of a full bridge inverter for induction heating cooking appliances with discontinuous current mode PFC control", in IEEE Power Electronics Specialists Conference, 2008, pp. 2948-2953.

[10] A. Salih, "IGBT for high performance induction heating applications", in Proc. 38th Annual Conference on IEEE Industrial Electronics Society, Oct. 2012, pp. 3274-3280.

[11] Viriya, et.al, "Analysis of High frequency Induction cooker with variable frequency power control", Power Conversion Conference, 2002. PCC Osaka 2002. Procedings of the Vol. 3, 5-2 April 2002 Page(s) 1507-1512 Vol.3.

[12] Chatterjee K., Ramanarayanan V. Optimum design of single switch resonant induction heater // Proc. IEEE Int. Symp. Industrial Electronics. - 1992. - P. 858-859.

[13] Hirota, I., Omori, H., Nakaoka, M. "Performance evaluations of single- ended quasi-load resonant inverter incorporating advanced-2nd generation IGBT for soft switching". IEEE int. Conf. on Power Electronics and motion control, San Diego CA, 1992, Vol.1, pp.223-228

[14] Cohen I.(1993), Evaluation and comparison of power conversion topologies, European Power Electronics Conf. (EPE) Rec., pp. 9-16.

[15] Llorente S., Monterde F., Burdio J.M. and Acero J. (2002), A comparative study of resonant inverter topologies used in induction cooker, IEEE Applied Power Electronics Conf. (APEC) Rec., pp. 1168-1174.

[16] Wang S., Izaki K., Hirota I., Yamashita H., Omori H. and Nakaoka, M. (1998), Induction heated cooking appliance using new quasi-resonant ZVS-PWM inverter with power factor correction, IEEE Trans Industry Applications., vol 34, no.4, pp.705-712.

[17] Umashankar S., Punna Srikanth., D. Vijay Kumar and D.P. Kothari, "Maximum Power Point Tracking Algorithms with DC-DC converters for Solar PV System", in International Journal of Electrical and Computer Engineering, vol 3, no 1, 2011, pp. 11-20.

[18] T. Vamsee Kiran and J. Amarnath, "Performance Comparision of PI, Sliding Mode and Fuzzy Logic Controllers for DTC of Three level Inverter Fed Induction Motor", in International Journal of Electrical and Computer Engineering., vol 4, no.1, 2012, pp.1-16.

\section{BIOGRAPHIES OF AUTHORS}
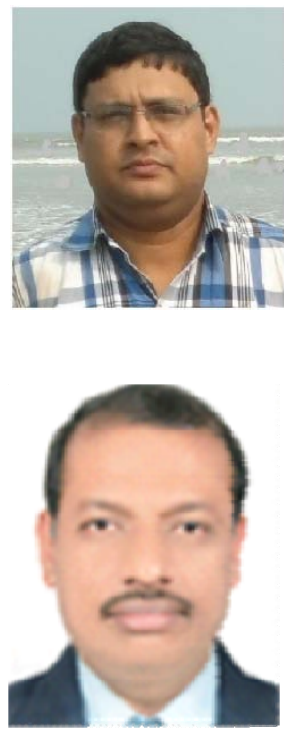

Avijit Chakraborty obtained his B.Sc degree in Physics (Honours) from the Calcutta University, West Bengal, India, in 2002 and obtained his B.Tech degree in Electrical Engineering from the Calcutta University, West Bengal, India, in 2005 and M.Tech degree in Electrical Engineering from the Calcutta University, West Bengal, India, in 2007. He is presently working as an Assistant Professor in Electrical Engineering at the Saroj Mohan Institute of Technology, Hooghly, West Bengal, India. His research interest includes Power Electronics, Electrical Machines, Power System, High frequency Power Electronic converters Renewable Energy Sources. At present he is engaged in research works on Induction based heating applications.

Pradip Kumar Sadhu received his Bachelor, Post-Graduate and Ph.D. (Engineering) degrees in 1997, 1999 and 2002 respectively in Electrical Engg. From Jadavpur University, West Bengal, India. Currently, he is working as a Professor in Electrical Engineering Department of Indian School of Mines, Dhanbad, India. He has total experience of 18 years in teaching and industry. $\mathrm{He}$ has four Patents. He has several journal and conference publications in national and international level. He is principal investigator of few Govt. funded projects. He has guided a large no. of doctoral candidates and M. Tech students. His current areas of interest are power electronics applications, application of high frequency converter, energy efficient devices, energy efficient drives, computer aided power system analysis, condition monitoring, lighting and communication systems for underground coal mines. 


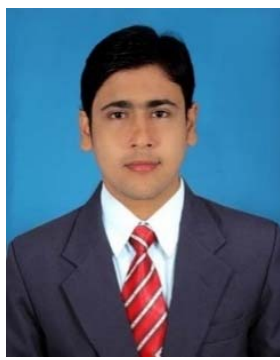

Kallol Bhaumik obtained his Diploma degree in Electrical Engineering from West Bengal State Council of Technical Education, West Bengal, India, in 2008 and obtained B.Tech degree in Electrical Engineering from the West Bengal University of Technology, West Bengal, India, in 2011. He also obtained M.Tech degree in Power Systems from the West Bengal University of Technology, West Bengal, India, in 2013. He is presently working as an Assistant Professor in Electrical Engineering at the Saroj Mohan Institute of Technology, Hooghly, West Bengal, India. His research interest includes Power Electronics, Non - Conventional Energy Sources, Electrical Machines, Power System, High frequency Power Electronic converters. At present he is engaged in research works on Induction based heating application

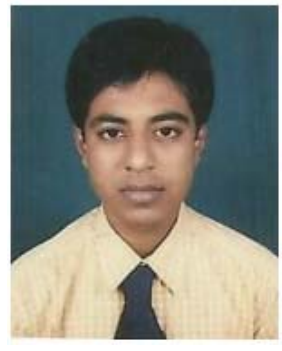

Palash Pal completed Diploma in Electrical Engineering from West Bengal State Council of Technical Education, West Bengal, India in 2003. He received his B.Tech Degree in Electrical Engineering from West Bengal University of Technology, West Bengal, India in 2006 and M.Tech. (Gold Medalist) in 2009 from same University. He has total experience of nine years in teaching. He is currently working as Principal In-Charge, Saroj Mohan Institute of Technology (SMIT-TIG), Guptipara, Hooghly-712512, West Bengal, India. He is presently pursuing Ph.D. programme at the Department of Electrical Engineering, Indian School of Mines, Dhanbad826004, India. He has several publications in Journals, International \& National conferences. His research interests include power electronics, induction heating, high frequency converters, high frequency heating, control systems and power systems.

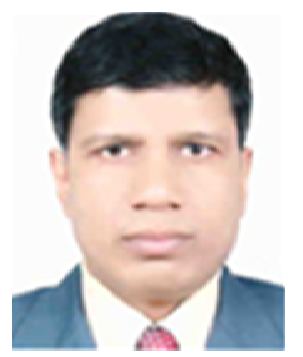

Nitai Pal received his B.Tech. and M.Tech. degrees in Electrical Engineering from University of Calcutta, West Bengal, India. He received his Ph.D. (Engineering) from Jadavpur University, West Bengal, India. He has total experience of twelve years in teaching. He is currently working as an Assistant Professor in the Department of Electrical Engineering, Indian School of Mines, Dhanbad, Jharkhand, India. He has several publications in Journals, International \& National conferences. He is the co-investigator of Govt funded project. His current areas of interest are Power electronics application, application of high frequency converters, energy efficient devices, energy efficient drives, lighting and communication systems for underground coal mines. 